\title{
SOME PECULIARTIES OF THE ROTATOR CUFF MUSCLES
}

\author{
Radomír Holibka*a, Alžběta Holibkováb, Stanislav Laichman ${ }^{b}$, Katherine Růžičkováb \\ a Clinic of Orthopedics, Teaching Hospital, 77520 Olomouc, Czech Republic \\ b Institute of Anatomy, Faculty of Medicine, Palacký University, 77515 Olomouc, Czech Republic
}

Received: November 20, 2003; Accepted: December 10, 2003

Key words: Shoulder joint / Rotator cuff muscles / Synovial sheaths / Muscular bursas

The authors studied the origin, course and insertion as well as some peculiarities of RC muscles on 25 cadaverous fixed limbs. They discovered that RC muscles exchange muscle bundles and are secured by synovial sheaths. They described the articular muscles in all of the observed muscles, including the deltoid muscle, which significantly stretch the capsule of the glenohumeral joint. They expressed the opinion that the subscapular bursa enhances motions in the shoulder joint. Due to the possibilities of arthroscopic diagnostic and treatment methods, they are convinced that more attention must directed to this issue from both the morphological and functional perspective.

\section{INTRODUCTION}

Trauma to the shoulder joint is one of the most common joint diseases of the upper limbs. The causes of limited motion of this joint are varied, from traumatic damage, overuse of the joint, hypovascularity to joint changes related to age. The rotator cuff muscles RC are a siginificant component of the shoulder joint. They cover and perfectly fixate the capsule of the shoulder joint by adhering to the capsule, thus replacing the not very functional ligaments of this joint. The muscles of the rotator cuff are also a component - the head - of the subacromial joint, which is a functional component of the shoulder joint and significantly contributes to motion in this joint. Trauma to the RC is, without a doubt, associated with subacromial impingement, which belongs to the most common shoulder joint injuries. Lately, the issue of RC study is making its way to the forefront of anatomical, diagnostic and surgical interests. Thorough anatomical knowledge of the structure of the shoulder joint and its surrounding muscles is a basic assumption for successful treatment, both conservative and surgical.

\section{MATERIALS AND METHODS}

In this contribution we focussed on the course and peculiarities of the RC muscles. For the study, we used cadaverous material obtained from the Department of Normal Anatomy. The material was fixated by injection with a solution of alcohol formaldehyde and glycerol, commonly used for fixating the cadavers of donors at this department. The age of the donors ranged from 45 to 79 years. Only material without any macroscopic pathological changes and with a well-developed musculature was used for this study. Genital changes of the individuals were not studied, because they were not the focus of our study, nor were they able to be seriously evaluated on the given material. On the 25 upper limbs, 14 right and 11 left, we determined the shape of the muscles, their course, their relation to the shoulder joint capsule, and their tendon insertions by classical anatomical preparation.

We described the following muscles: supraspinatus muscle, infraspinatus muscle, teres minor muscle, subscapularis muscle.

\section{RESULTS}

The individual muscles were covered by the deltoid muscle and after its removal the capsule of the shoulder joint was exposed (Fig. 1). The subdeltoid bursa as well as the subacromial bursa was seen at the insertion and together with the capsule of the shoulder joint create the cavity of the false subacromial joint.

The supraspinatus muscle - in all the observed cases, the muscle was covered by a thick fascia, which was fixed to the superior scapular margin, the medial scapular margin and by a thick aponeurosis to the spine of the scapula up to the acromion, whereby it creates an isolated fascial bed for this muscle. The muscle runs under the coracoacromial ligament and inserts into the upper portion of the greater tubercle of the humerus. The muscle bundles of the upper part of the infraspinatus muscle join to the external one-third of the lower part of the muscle. The tendon is provided with a synovial sheath, which merges into the capsule of the shoulder joint (Fig. 2, 3), together with superficial muscle bundles of the articular muscles into the joint capsule (Fig. 7).

The infraspinatus muscle - the muscle originated in the infraspinal fossa by three pinnate origins ( $80 \%)$. Bipinnate and monopinnate muscle origins were only observed in 5 cases $(20 \%)$. Beginning from the lower surface of 
the spine of the scapula, the most proximal muscle bundles from the upper portion of the muscle joined to the supraspinatus muscle. The muscle was covered by a thick fascia that was fixed to the spine of the scapula, the medial margin of the scapula and was inserted to the lateral margin of the scapula up to the proximal portion of the humerus. A clearly visible intermuscular septum divided the fascial area of this muscle from the teres minor muscle (Fig. 4). In the area where it changed to tendon, it was provided with a synovial sheath (Fig. 5, 6). Superficial muscle bundles passed along the superficial portion of the synovial sheath into the articular capsule of the shoulder joint (Fig. 7). It was inserted at the central level of the greater tubercle of the humerus.

The teres minor muscle - was a narrow muscle which originated at the central portion of the lateral margin of

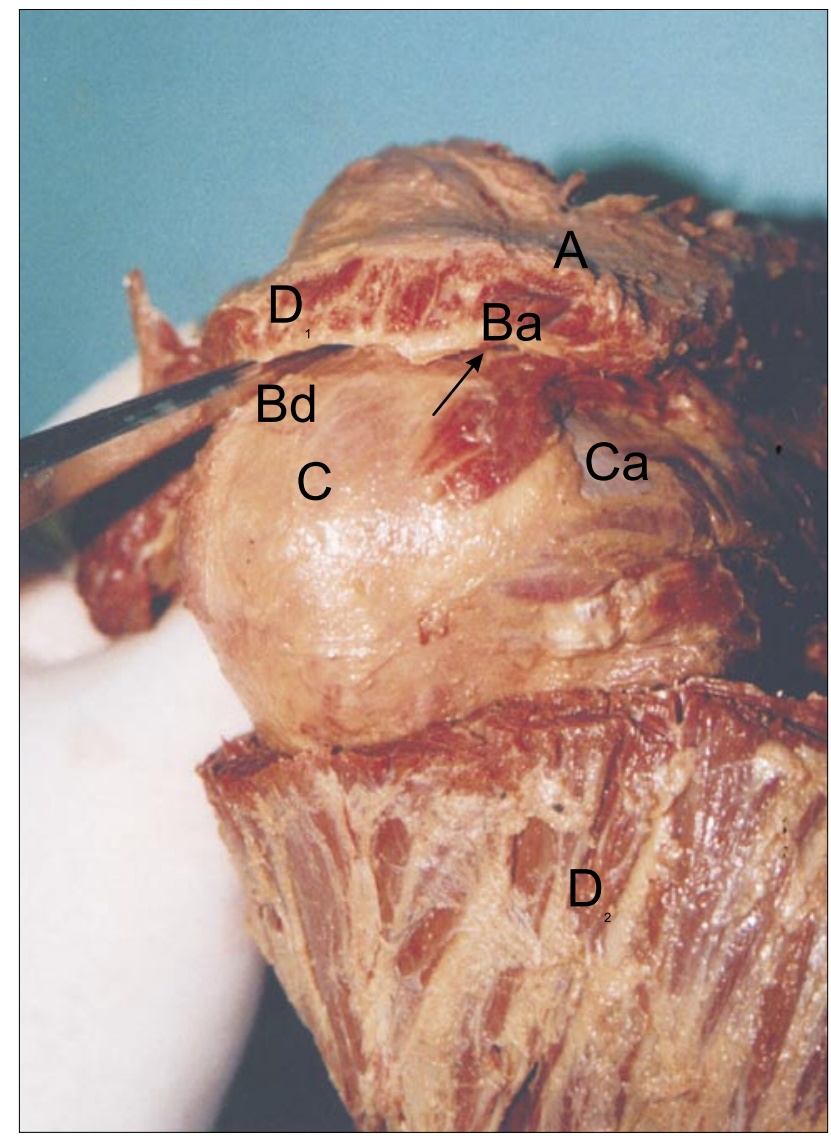

Fig. 1. C - humerus head-covered by the joint capsule

A - acromion

$\mathrm{D}_{1}$ - origo deltoidei $\mathrm{m}$.

$\mathrm{D}_{2}$ - insertio deltoidei $\mathrm{m}$.

$\mathrm{Ca}$ - capsula articularis

$\mathrm{Bd}$ - bursa subdeltoidea

$\mathrm{Ba}$ - bursa subacromialis the scapula, a significant portion of the muscle bundles also began from the lower portion of the intermuscular septum (Fig. 4). A part of these bundles was laterally added to the infraspinatus muscle. The relatively narrow muscle continued into a fairly thick tendon, which inserted on the lower portion of the greater tubercle of the humerus, distally to the collum anatomicum of the humerus up to the beginning tendon of the medial head of the triceps muscle. It was also provided with a synovial sheath (Fig. 4, 5, 6). A portion of the superficial bundles create the articular muscles of the capsule of the shoulder joint (Fig. 7).

The subscapularis muscle - its origin filled the entire subscapular fossa. The origin is re-inforced by several ligament bands (Fig. 8), that leave muscular ridges on the surface of the scapula. The extensive insertion tendon is

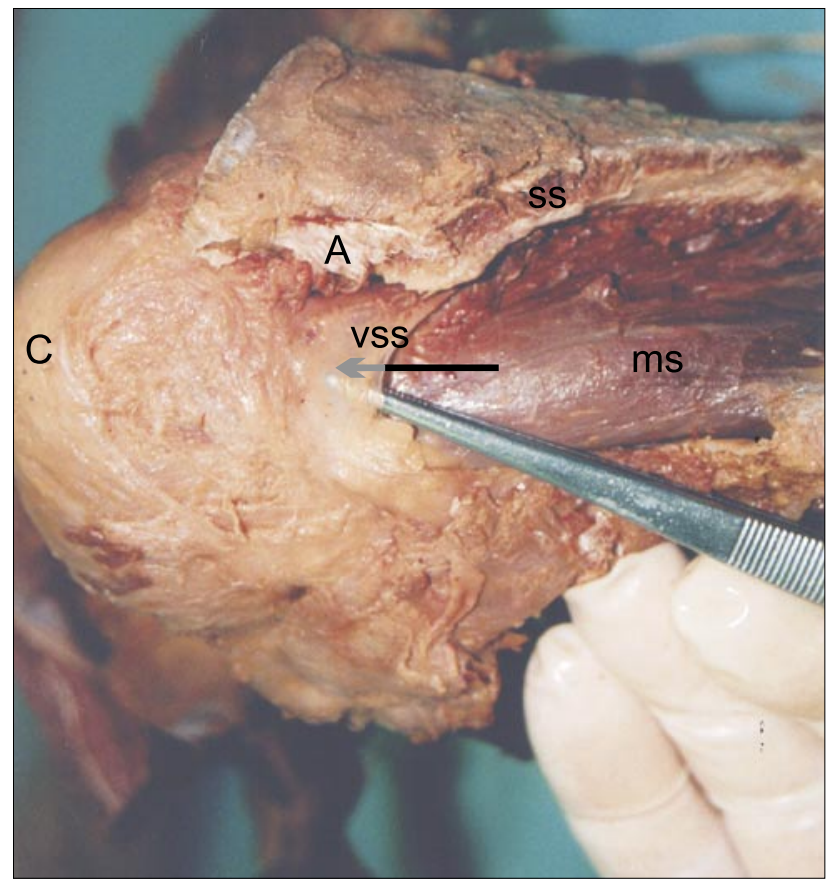

Fig. 2. A - acromion - with the lateral portion cutt off C - caput humeri ss - spina scapulae ms - supraspinatus $m$. vss - vagina synovialis supraspinati $\mathrm{m}$.

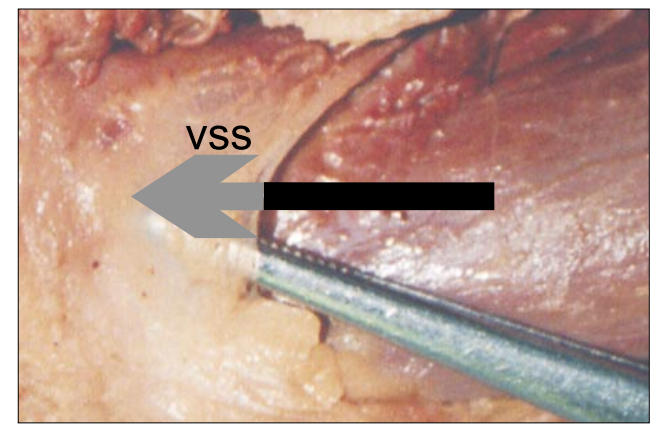

Fig. 3. vss - vagina synovialis supraspinati $m$. 


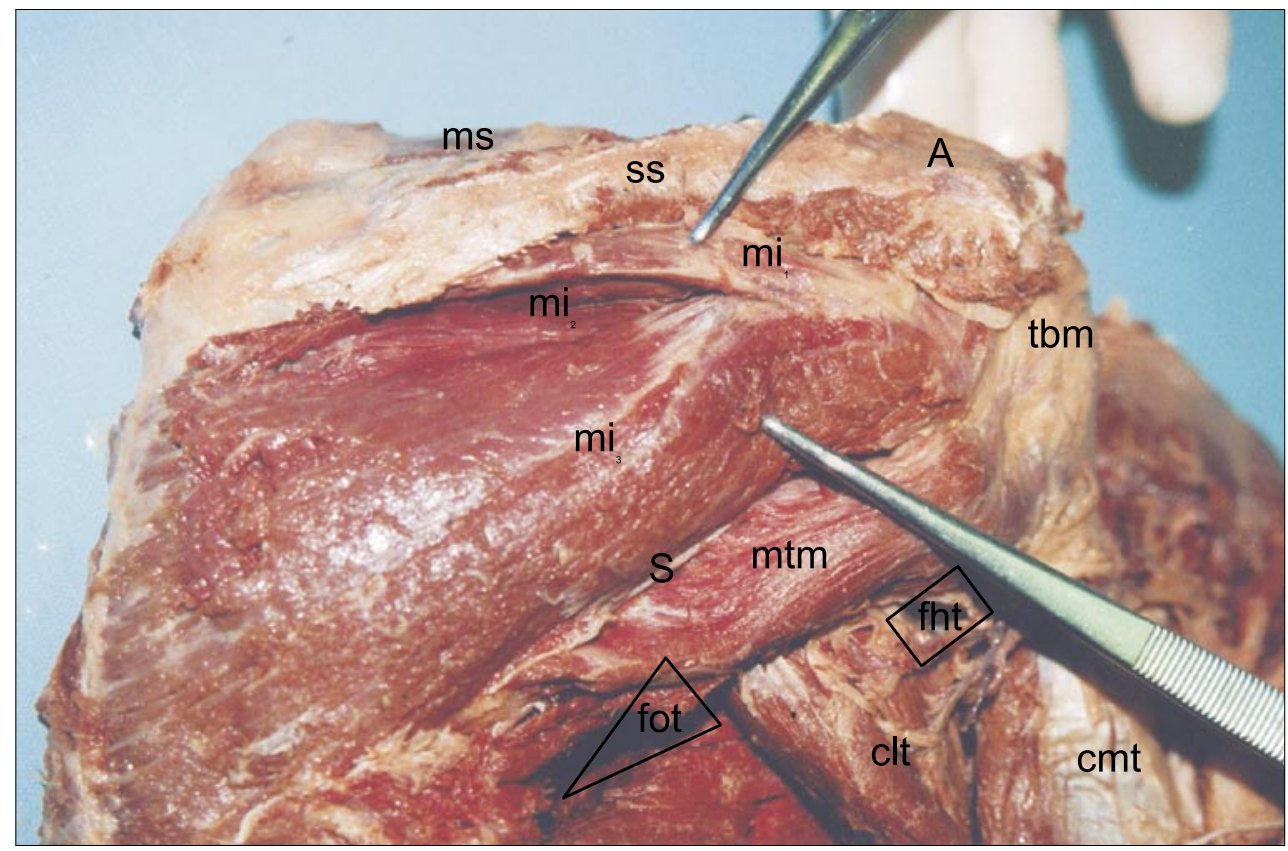

Fig. 4. A - acromion, ss - spina scapulae, tbm - tuberculum maius humeri, $\mathrm{ms}$ - supraspinatus $\mathrm{m}$., $\mathrm{mi}_{1}, \mathrm{mi}_{2}, \mathrm{mi}_{3}$ - individual portion of infraspinatus $\mathrm{m} ., \mathrm{S}$ - septum of infraspinatus $\mathrm{m}$., $\mathrm{mtm}$ - teres minor $\mathrm{m}$., fht - foramen humerotricipitale, fot - foramen omotricipitale, clt - caput longum tricipitis brachii m., cmt - caput mediale tricipitis brachii $\mathrm{m}$.
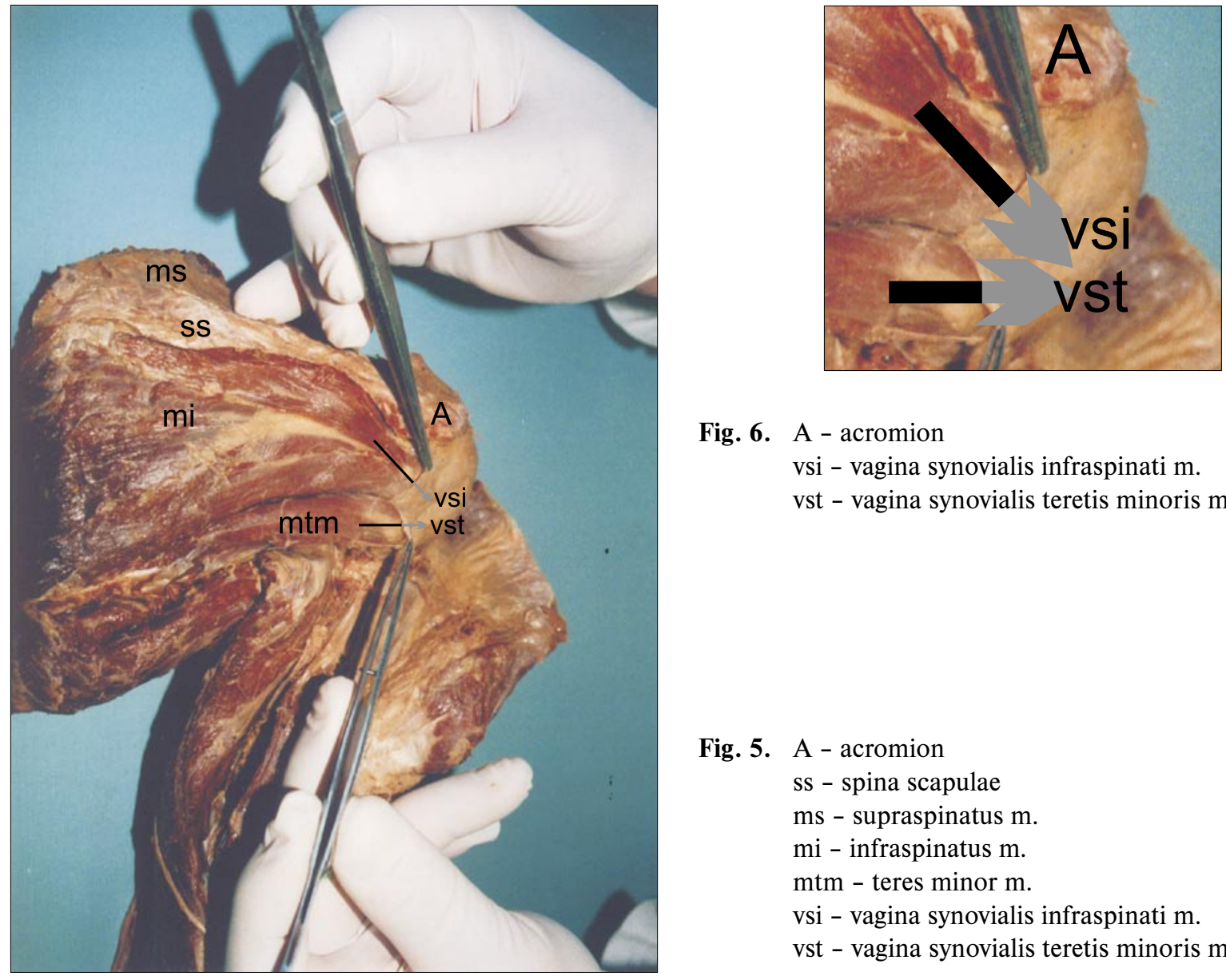

Fig. 6. A - acromion

vsi - vagina synovialis infraspinati $\mathrm{m}$. vst - vagina synovialis teretis minoris $\mathrm{m}$.

Fig. 5. A - acromion

ss - spina scapulae

$\mathrm{ms}$ - supraspinatus $\mathrm{m}$.

$\mathrm{mi}$ - infraspinatus $\mathrm{m}$.

$\mathrm{mtm}$ - teres minor $\mathrm{m}$.

vsi - vagina synovialis infraspinati $\mathrm{m}$.

vst - vagina synovialis teretis minoris $m$. 


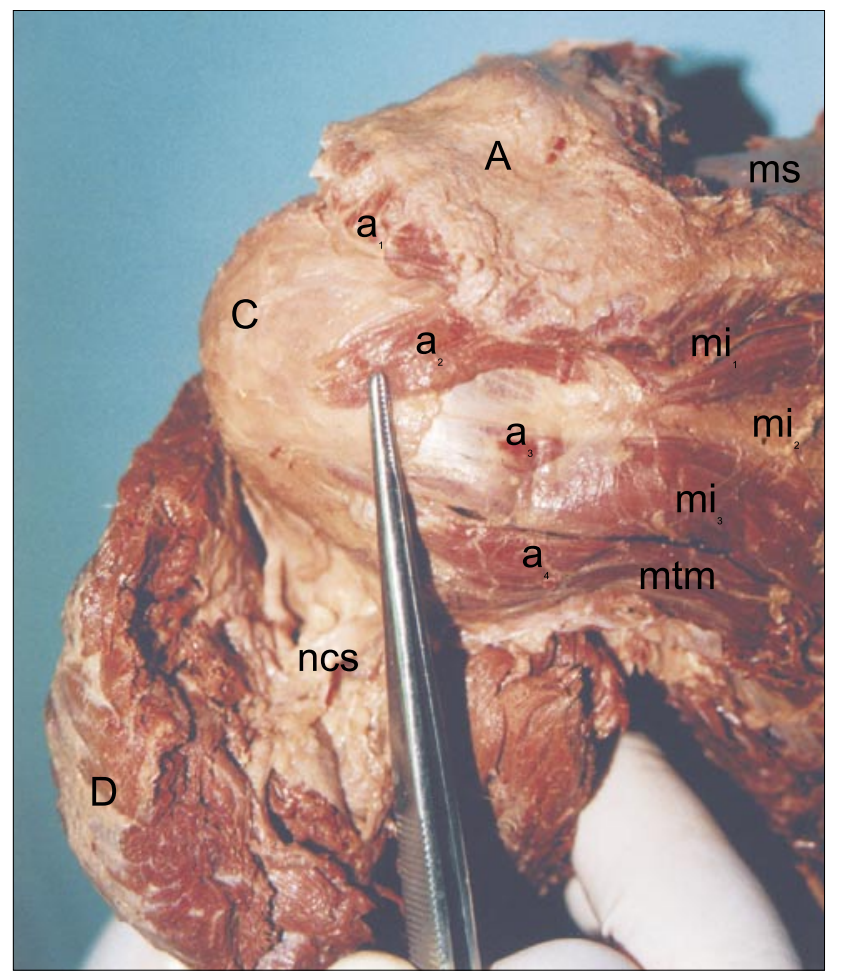

Fig. 7. A - acromion

C - caput humeri

D - preparated deltoidei $\mathrm{m}$.

ms - supraspinatus $m$.

$\mathrm{mi}_{1}-\mathrm{mi}_{3}$ - individual portions of infraspinatus $\mathrm{m}$. $\mathrm{mtm}$ - teres minor $\mathrm{m}$.

$a_{1}$ - articularis m. - deep bundles deltoidei $m$.

$\mathrm{a}_{2}$ - articularis $\mathrm{m}$. - superficial bundles supraspinati m.

$a_{3}$ - articularis m. - superficial bundles infraspinati m.

$\mathrm{a}_{4}$ - articularis m. - superficial bundles teretis minoris $\mathrm{m}$.

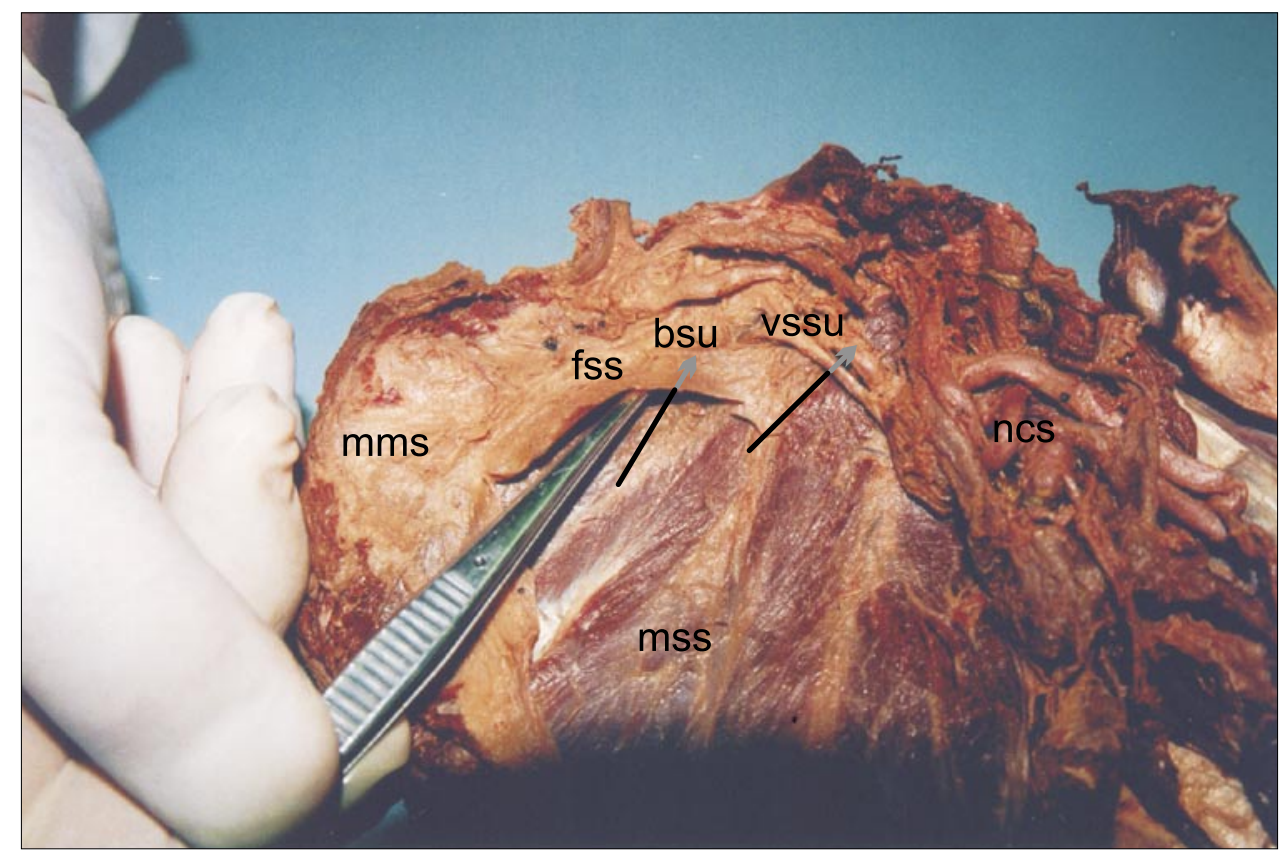

Fig. 8. mss - subscapularis m., mms - margo medialis scapulae, ncs - neuro-arterial bundle of the arm, vssu - vagina synovialis subscapularis m., bsu - bursa subscapularis, fss - fascia subscapularis 
provided with a synovial sheath, passes under the coracoid process of the scapula to the frontal surface of the shoulder joint and is fixed to the lesser tubercle of the humerus along the medial margin of the synovial sheath of the long head of the biceps muscle. A massive subscapular bursa is located between the muscle and the joint capsule, which always communicated with the cavity of the joint capsule in our specimens. In this muscle, the muscle bundles also pass into the joint capsule. The muscle is covered by a thick fibrous aponeurosis, which separates it and is partly involved with the false thoracoscapular joint.

\section{DISCUSSION}

With the expansion of shoulder joint arthroscopic operations, the RC muscles are becoming a focal interest of orthopedic surgeons and traumatologists. A large number of non-bleeding reparations of damaged $\mathrm{RC}$ muscles has been performed. Great interest is also dedicated to the significance of the long head of the biceps muscle in stabilising and reconstructing the shoulder joint ${ }^{1-5}$.

The same interest is given to joint biomechanics ${ }^{6}$ and intracapsular ligaments ${ }^{7-11}$.

From detailed anatomical study, we have pointed out some common characteristics. The muscles of the external rotator group exchange muscle bundles with each other, which potentiates the functional power and action speed of the muscles. In their monographic study, anatomists and orthopedic surgeons have brought attention to this $^{12,13}$. Otherwise, the origin and insertion of the muscles are only presented in textbook form ${ }^{14,15}$.

Synovial sheaths were demonstrated with all muscles. In this unrestrained, most motile joint in the body, the $\mathrm{RC}$ tendons are the place of the fastest movement in the body, external rotation and quick transition to supination, where overstrain of the glenohumeral ligaments occurs. The synovial sheaths offer a significant security mechanism for exponated rotator tendons ${ }^{16,17}$.

The articular muscles are the continuation of muscle bundles of all RC muscles and deep muscle bundles of the deltoid muscle into the joint capsule. They are clearly visible and are distributed in all directions of motion. They definitely have an indispensible role during rotation movements in the shoulder joint and probably not only during protection against incarceration of the joint capsule.

The subscapular bursa remains an unanswered question. Most textbooks indicate that it can be associated with the joint capsule. We proved this association in all observed joints. We are of the opinion, that during maximum rotation it allows for easier shifting of the humeral head in the joint capsule.

\section{CONCLUSION}

1. The authors described the course of the RC muscles, by detailed preparation on 25 anatomical preparations.
2. They stated, that the external RC muscles exchange their muscle bundles.

3. They discovered, that the tendons of the RC muscles are provided with a synovial sheath.

4. They described the articular muscles in all RC muscles, including the deltoid muscle.

5. They determined, that the subscapular bursa exponates motion in the shoulder joint.

\section{REFERENCES}

1. Dvořák V. (1997) Poranění SLAP - superior labrum anterior posterior. Acta Chir Orthopaed Čechosl 64, 161-165.

2. Heers G, O'Driscoll SW, Halder AM, Zhao S, Mura N, Berglund LJ, Zobitz ME, An KN. (2003) Gliding properties of the long head of the biceps brachii. Journal of Orthopaedic Research $21,162-166$

3. Hyman JL, Waren RF. (2001) Extra-articular Origin of Biceps Brachii. Arthroscopy. The Journal of Arthroscopic and Related Surg 17, No. 7, 1-3.

4. Machálek L, Holibková A, Charamza J, Cach A, Holibka R. (1998) A contribution to the anomalies of the arm flexors. Acta Univ Palacki Olomuc (Olomouc) Fac Med 141, 61-64.

5. Tang CY, Mak A FT, Hung LK, Wong HS, Pacaldo T. (2001) Stability of Reconstructed Paralysed Shoulders Using a Reflected Long Head Biceps Technique. Journal of Biomechanical Engineering 123, 227-233.

6. Holibková A, Laichman S, Holibka R, Zacpalová Z. (2002) The influence of blood supply on function and rehabilitation of the shoulder articulation. The Procceedings of Abstracts of the Inrenational Scientic Conference PHYSICAL EDUCATION AND SPORT 2002, Liberec - Euroregion Nisa, p. 20.

7. Brenneke SL, Reid J, Ching RP, Wheeler DL. (2000) Glenohumeral kinematics and capsulo-ligamentous strain resulting from laxity exams. Clinical Biomechanics 15, 735-742.

8. Brügger A. (1980) Die Erkrankungen des Bewegungsapparates und seines Nervensystems. (2nd ed.), Gustav Fischer Verlag Stuttgart, New York.

9. Eberly VC, McMahon PJ, Lee TQ. (2002) Variation in the Glenoid Origin of the Anteroinferior Glenohumeral Capsulolabrum. Clin Orthop 400, 26-31.

10. Rafii M, Firooznia H, Golimbu C, Minkoff J, Bonamo J. (1986) CT arthrography of capsular structures of the shoulder. American Journal of Roentgenology 146, 2, 361-367.

11. Reis MT, Tibone JE, McMahon PJ, Lee TQ. (2002) Cadaveric Study of Glenohumeral Translation Using Electgromagnetic Sensors. Clin Orthop 400, 88-92.

12. Bartoníček J, Doskočil M, Heřt J, Sosna A. (1991) Chirurgická anatomie velkých končetinových kloubů. (1nd ed.). Avicenum, Praha.

13. Miller SL, Gladstone JN, Cleeman E, Klein MJ, Chiang AS, Flatow EL. (2003) Anatomy of the Posterior Rotator Interval: Implications for Cuff Mobilization. Clin Orthop 408, 152-156.

14. Borovanský L, et al. (1976) Soustavná anatomie člověka. díl I., red. Čihák, R. (5nd ed.). Avicenum, Zdravotnické nakladatelství, Praha.

15. Čihák R. (1987) Anatomie I. (1nd ed.). Avicenum, Zdravotnické nakladatelství, Praha.

16. Carillon Y, Noel E, Fantino O, Perrin-Fayole O, Tran-Minh VA. (1999) Magnetic resonance imaging findings in idiopathic adhesive capsulitis of the shoulder. Revue du Rhumatisme (English Edition) 66, 201-206.

17. Halpern AA. (1979) Massive synovial cyst of the shoulder causing vascular compromise. A case report. Clin Orthop 143, 151-154. 